\title{
RECTAL ULCER COMPLICATED WITH LOWER GASTROINTESTINAL BLEEDING. A CASE STUDY
}

\section{Ana-Maria BOTIANU ${ }^{1 凶}$, Dana POPESCU ${ }^{2}$, Petre V.H. BOTIANU ${ }^{3}$, Geanina SCOIPAN ${ }^{1}$, Anca LACATUS ${ }^{1}$, Claudia GAVRIS ${ }^{1}$}

${ }^{1}$ Transylvania University, Faculty of Medicine, Department of Medical and Surgical Sciences, Internal Medicine, Brasov, Romania

${ }^{2}$ Topmed Medical Center, Rheumatology Department, Targu-Mureș, Romania

${ }^{3}$ University of Medicine, Pharmacy Science and Technology „G.E. Palade“, Surgery 3 Discipline, Targu Mures, Romania

Received 01 May 2020, Accepted 13 May 2020

https://doi.org/10.31688/ABMU.2020.55.2.21

\section{Abstract}

Introduction. Non-steroidal anti-inflammatory drugs (NSAID) use for adequate pain control and antipyretic effect is common worldwide. Multiple side effects (gastrointestinal, cardiovascular, renal) are well known and despite preventive measures for the upper digestive tract, less is known and can be done on the lower gastrointestinal tract. Several risk factors have been identified, especially age over 65 years, pre-existing mucosal lesions, concomitant aggressive factors (corticotherapy, antithrombotic medication, radiotherapy).

Case presentation. We present the case of a 76-year-old male, who developed a deep hemorrhagic solitary rectal ulcer following NSAID administration, on a pre-existing minor post-radiation erosion and chronic radiation proctitis.

Conclusions. The case is a reminder of NSAID gastrointestinal complications; though well documented on the upper GI tract, they should not be neglected on the lower tract, especially in elderly patients with pre-existing lesions or concomitant aggressive factors. Limited time exposure doesn't seem to be a guarantee

\section{Résumé}

Ulcère rectal compliqué d'une hémorragie gastro-intestinale: rappel sur les effets gastro-intestinaux des anti-inflammatoires non-stéroïdiens

Introduction. Les anti-inflammatoire non-stéroïdiens (AINS) sont fréquemment utilisés dans le monde entier en tant qu'antalgiques et antipyrétique. Les effets secondaires multiples (gastro-intestinaux, cardio- vasculaires, rénaux) sont bien connus et malgré le fait d'avoir actuellement le choix des mesures préventives pour les complications digestives supérieures, on connait très peu en ce qui concerne la prévention des complications digestives inferieures. Il y a plusieurs facteurs de risque identifiés, surtout l'âge au-dessus de 65 ans, les lésions muqueuses préexistantes, les facteurs d'agression associés (corticothérapie, anticoagulants, radiothérapie).

Rapport du cas. Nous rapportons le cas d'un patient âgé de 76 ans qui présente un ulcère rectal solitaire, profond et hémorragique, survenu à la suite de l'utilisation d'AINS, dans un contexte préexistant d'érosion 
of avoiding more serious complications, such as bleeding or deeper lesions.

Keywords: lower gastrointestinal bleeding, NSAID, hemorrhagic rectal ulcer.

\section{Abbreviations list:}

NSAID - non-steroidal anti-inflammatory drugs; OTC - over the counter; GI - gastrointestinal; NBI narrow band imaging.

\section{INTRODUCTION}

Non-steroidal anti-inflammatory drugs (NSAID) are among the most common used drugs in the world, especially for adequate pain control and antipyretic effect. NSAID-induced inhibition of mucosal prostaglandin synthesis is the major mechanism of gastrointestinal mucosal injury ${ }^{1}$. 1-2\% of NSAID users experience serious gastrointestinal events ${ }^{2}$ and $30-50 \%$ of them have endoscopic lesions (ranging from mild erosions to hemorrhagic ulcerations), with or without significant clinical symptoms (abdominal pain, nausea, vomiting) before bleeding ${ }^{2,3}$. Some preventive measures can be used to reduce upper digestive tract complications (endoscopic lesions and especially bleeding), such as use of proton pump inhibitors or selective cyclooxigenase-2 inhibitors, or enteral nutrition $^{4}$. Less is known and can be done to prevent lower gastrointestinal (GI) complications following NSAID administration. Lately, NSAID-induced upper GI tract complications have decreased, but NSAID-related problems in the lower gastro-intestinal (GI) tract have increased ${ }^{5}$.

\section{Case presentation}

We present the case of a 76-year-old male, who presented in February 2016 in an ambulatory unit for mild repeated proctorrhagia and intense anal discomfort, both following NSAID use (2 tablets of Ibuprofen of $600 \mathrm{mg}$, orally, self-administered for a mild upper respiratory tract infection and flu-like symptoms). Otherwise, the patient was in good clinical status, hemodynamically stable, afebrile. Abdominal examination revealed no tenderness. Complete blood count showed mild anemia, with a hemoglobin value of $10 \mathrm{~g} / \mathrm{dL}$, no renal or hepatic impairment. mineure des muqueuses post radiation et d'une rectite radique chronique.

Conclusions. Ce cas représente un rappel sur la toxicité gastro-intestinale des AINS, bien connue sur le tractus digestif supérieur, mais qui doit être également prise en compte pour le tractus digestif inférieur surtout chez les patients âgés présentant des lésions préexistantes ou des facteurs d'agression associés. Le temps réduit d'utilisation ne semble pas d'être une garantie en ce qui concerne la prévention des complications graves comme l'hémorragie ou les lésions profondes.

Mots-clés: saignement gastro-intestinal inférieur, AINS, ulcère rectal hémorragique.

Patient's personal history included several events: in 2010, he was diagnosed with prostate cancer, treated with bilateral orchiectomy and external beam pelvic radiotherapy during 2011 (finished), followed by hormone therapy (androgen deprivation-Zoladex). Afterwards, the oncologic evolution was good, with no significant clinical or biological impairment. The patient had no significant cardio-vascular, pulmonary, renal or hepatic comorbidities. In December 2013, the patient presented moderate anal discomfort, mostly pain at defecation, but no rectal bleeding, abdominal pain or weight loss. He had a normal complete blood count, no weight loss or other alarm symptoms. At that moment, lower GI endoscopy was performed and revealed the following: a solitary rectal superficial ulcerated lesion, with no macroscopic signs of malignancy. Other associated lesions at that moment included chronic radiation colitis (multiple spotted telangiectasias), left colon uncomplicated diverticulosis and small internal hemorrhoids.

Due to new onset symptoms, in February 2016, lower GI endoscopy was repeated and revealed a much deeper rectal ulcer with stigmata of recent hemorrhage, at the same spot of the previous superficial ulcerated lesion, most probably aggravated due to recent NSAID use. The treatment consisted in discontinuation of NSAID, rifaximine 2 tbs $\mathrm{x} 3$ times per day (10 days), topical treatment with hyaluronic acid suppositories for 2 weeks. The patient had a very good clinical evolution, with spectacular quick remission of pain, while bleeding stopped the next day. In May 2016, on patient's request (fear of prostate cancer invasion and relapse), lower GI endoscopy was repeated, which revealed mucosal healing, only a small linear scar with no signs of malignancy (macro- and microscopic examination). 


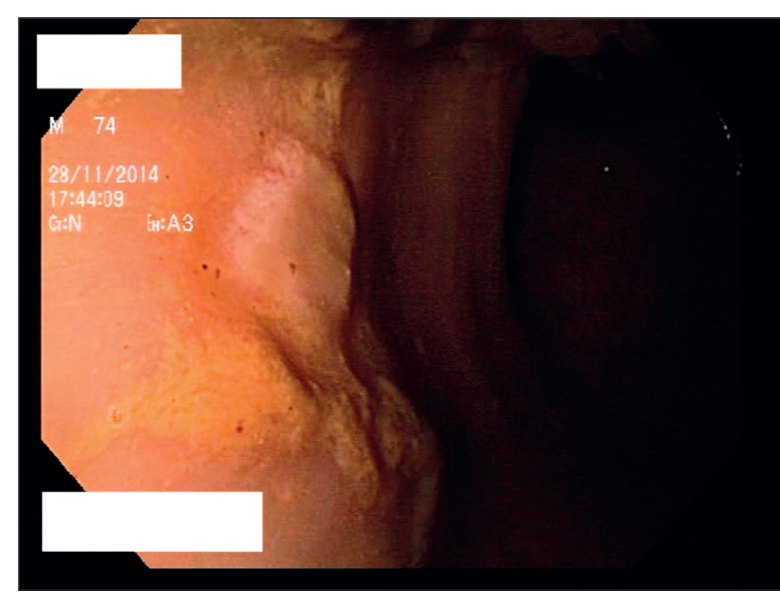

Figure 1a. Minimal rectal ulceration following pelvic therapy.

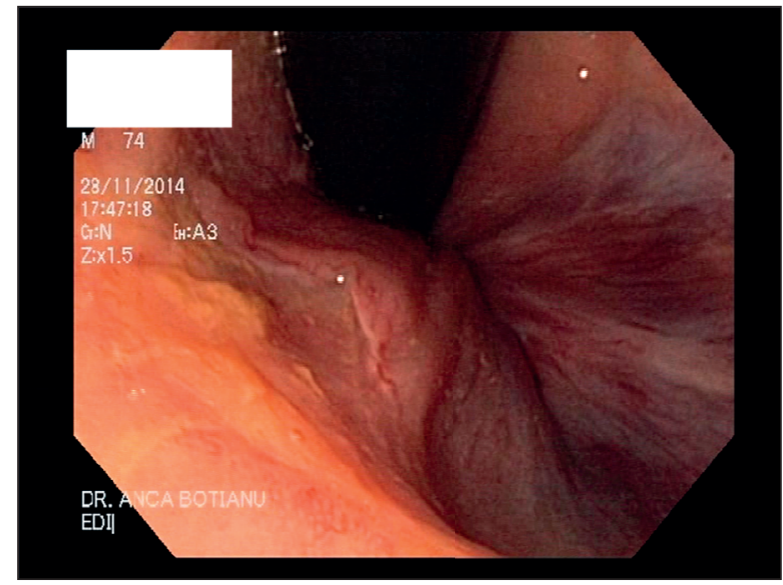

Figure 1c. Same lesion, detail in retroverse vision of the lower rectum, just above the anal verge.

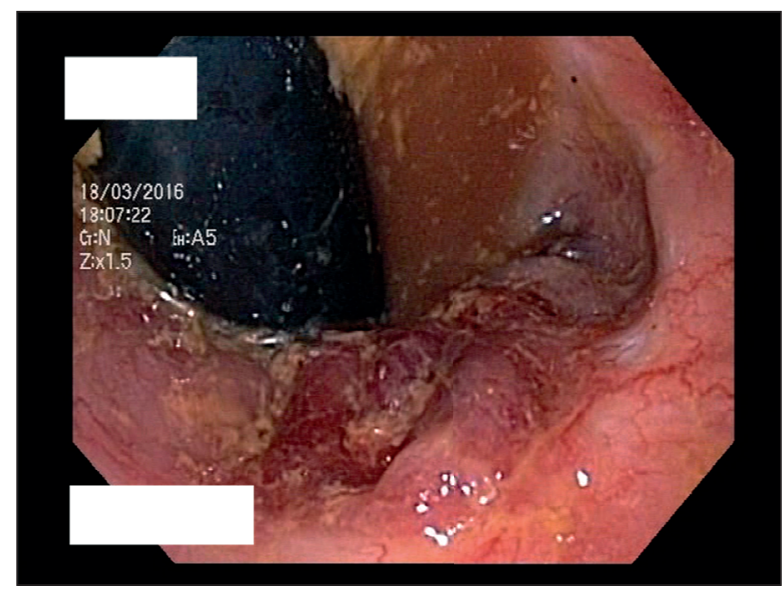

Figure 2a. Larger rectal ulcer, following NSAID administration.

\section{Discussion}

Both over the counter (OTC), as well as prescription-based NSAID use, is a common practice worldwide, mostly for adequate pain control, but

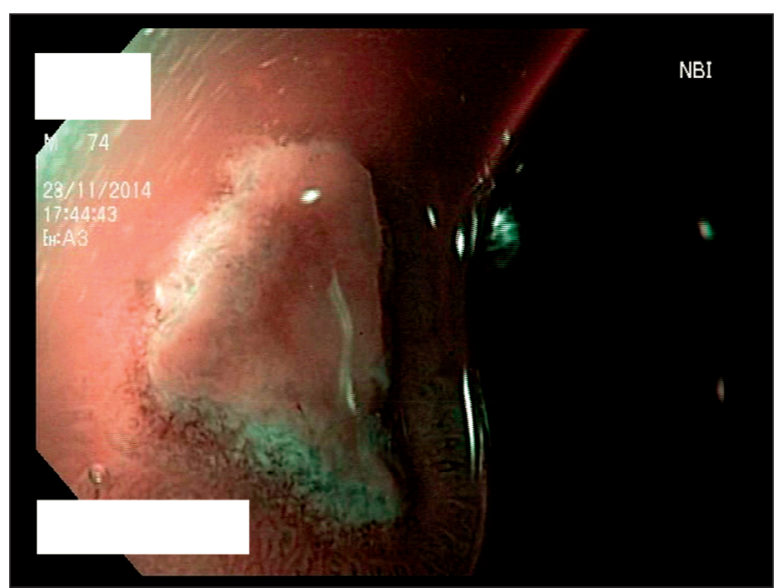

Figure 1b. Same lesion, detail in NBI (narrow band imaging) examination, no sign of malignancy.

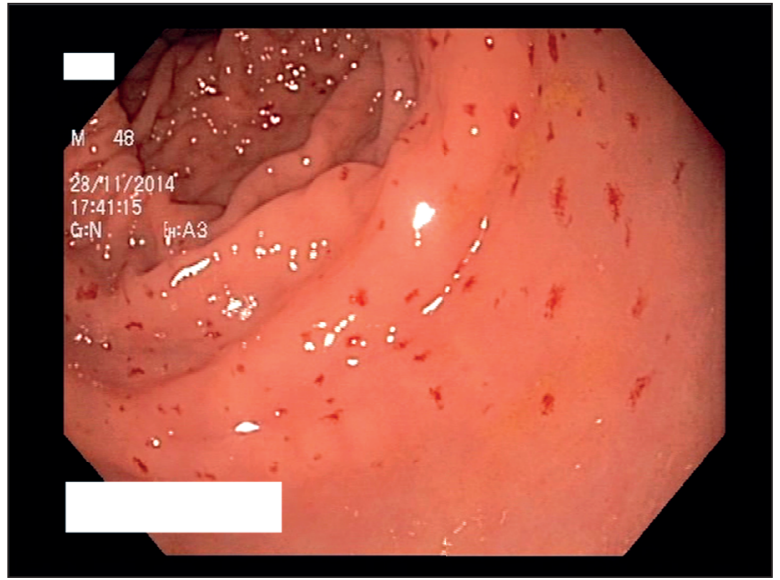

Figure 1d. Multiple diffuse telangiectasias, left sided radiation colitis

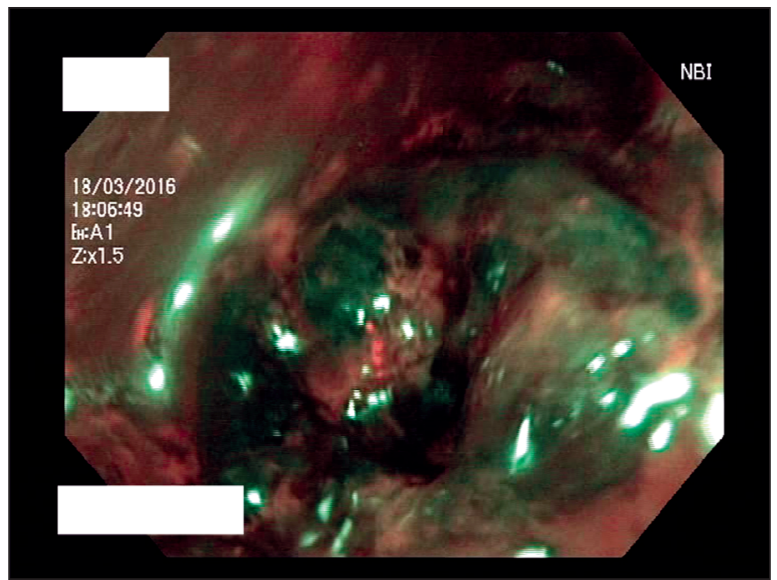

Figure 2b. Same lesion, closer detail in NBI examination.

also for mild inflammatory diseases, especially respiratory tract infections or common flu-like symptoms ${ }^{6}$.

NSAID use has been largely associated with multiple side effects (cardiovascular, renal, gastrointestinal) 


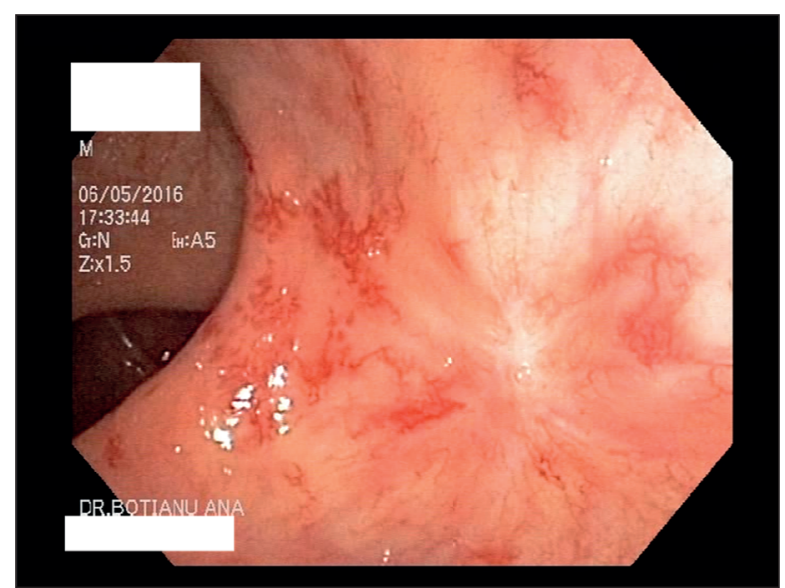

Figure 3. Mucosal healing, minimal linear scar with no macroscopic signs of malignancy.

and some patients are at increased risk? In 2005, The United States Food and Drug Administration (FDA) released a scientific statement emphasizing „the importance of using the lowest effective dose for the shortest duration possible if treatment with an NSAID is warranted for an individual patient ${ }^{\text {" }}$. GI side effects are more common than cardiovascular or renal ones ${ }^{7}$, and in the United States they represent the most common drug-related side effects. GI complications include upper and lower tract bleeding and, to a lesser extent, obstructions and perforations ${ }^{8}$. Several risk factors for GI bleeding have been identified: age over 60-65 years old, high-dose or multiple NSAID use, simultaneous use of other drugs (aspirin or other antithrombotic therapy, corticotherapy, selective serotonin reuptake inhibitors), hemodialysis, history of gastrointestinal injury9. Upper GI tract lesions are more frequent than lower ones, despite latter are increasing, and both have relatively constant morbidity and mortality rates ${ }^{8,10}$. Damage to the lower GI tract has not been widely studied and remains poorly characterized, despite increased importance ${ }^{11}$. Several prevention measures are available for upper GI bleeding: concomitant use of proton pump inhibitors, eradication of Helicobacter pylori, etc. However, limited prevention measures are available for lower GI bleeding: avoidance of non-aspirin NSAID use in patients with a history of acute lower GI bleeding, especially if secondary to diverticulosis or angiectasis, avoidance of aspirin for primary prevention of cardiovascular events in most patients with lower GI bleeding ${ }^{5,12,13}$. Consistent protective measures are also lacking in current guidelines or medical literature ${ }^{12,13}$.

In our patient, we can identify several risk factors: age over 65 years, pre-existing neoplasia (prostate cancer) and pre-existing multiple colonic lesions as a possible cause for lower GI bleeding (left sided colonic diverticulosis, chronic radiation colitis, hemorrhoids, radiation induced solitary rectal ulcer). However, serial endoscopic examination showed the aggravating effect of NSAID use on a minor pre-existing lesion, with evolution from mild erosion to deep hemorrhagic ulcer. Another fact to be considered is the limited administration, with only 2 tablets of NSAID, so despite limited but rather high dosage, important mucosal damage and complications appeared. The most important risk factors in this case seem to be age, but mostly the personal history with radiation colitis that predisposed to hemorrhagic ulcer, despite limited time exposure to the aggressive factor.

External radiotherapy is a common treatment for a wide range of cancers, pelvic radiotherapy being used mostly for gynecologic cancers in women, prostate cancer in men, as well as rectal cancer in both sexes. Approximately $70 \%$ of all cancer patients receive radiotherapy in the course of their disease, while radiotherapy plays a central role in $25 \%$ of all cancer treatments ${ }^{14}$.

Radiation injury can present acutely during radiotherapy or soon after, because of acute mucosal injury and inflammation, or it can present insidiously within few months or sometimes even years after radiotherapy, due to a chronic process of transmural fibrosis and vascular sclerosis, as in the case of our patient ${ }^{15}$. Treatment of delayed radiation injury is difficult, as it is often refractory, but several therapeutic modalities are available, with a wide range of clinical results ${ }^{15-18}$. Topical agents such as formalin ${ }^{19}$ or butyrate enemas were reported to improve symptoms in the acute setting, but with no impact on chronic radiation proctitis ${ }^{20}$. Corticotherapy administered as steroid enemas may alleviate symptoms, but has no proven impact on mucosal healing ${ }^{14}$. One of the most promising therapies seems to be hyperbaric oxygen $^{21}$, while antioxidants still need to be studied and validated $^{14,22}$. Hyperbaric oxygen was suggested to exert its therapeutic role in chronic radiation proctitis through induction of neovascularization that reverses tissue hypoxia, with trophic effect on vasculogenic stem cells ${ }^{21,23}$. In our patient, chronic radiation colitis was practically clinically asymptomatic and endoscopic lesions were minimal until NSAID administration, so no chronic treatment was needed before.

\section{Conclusions}

The case illustrates important NSAID-related mucosal injury and toxicity on the lower GI tract after very limited time exposure, in a patient with a few risk factors: age and pre-existing multiple lesions. Since limited preventive measures are available 
on the lower GI tract, two key messages should be remembered: 1) before prescribing NSAIDs, it is mandatory to evaluate pre-existing risk factors, especially mucosal GI lesions, though cardiovascular or renal problems should never be neglected; 2) OTC administration should probably be limited in the future, especially in elderly patients with comorbidities and possible hidden risk factors, in whom close medical supervision or direct counselling would be a better option.

\section{Author Contributions:}

A.B., G.S., A.L., C.G., P.B. and D.P. were responsible for the diagnostic procedures, clinical diagnosis, follow-up and treatment decisions. A.B., A.L., G.S. and D.P. wrote the manuscript. All authors have read and agreed to the published version of the manuscript.

\section{Compliance with Ethics Requirements:}

„The authors declare no conflict of interest regarding this article"

"The authors declare that all the procedures and experiments of this study respect the ethical standards in the Helsinki Declaration of 1975, as revised in 2008(5), as well as the national law. Informed consent was obtained from the patient included in the study"

"No funding for this study"

\section{Acknowledgements:}

None

\section{References}

1. García-Rayado G, Navarro M, Lanas A. NSAID-induced gastrointestinal damage and designing GI-sparing NSAIDs. Expert Rev Clin Pharmacol. 2018;11(10):1031-1043.

2. Sostres C, Gargallo CJ, Lanas A. Nonsteroidal anti-inflammatory drugs and upper and lower gastrointestinal mucosal damage. Arthritis Res Ther. 2013;15(Suppl 3). https://doi. org/10.1186/ar4175.

3. Lim YJ, Yang CH. Non-steroidal anti-inflammatory drug-induced enteropathy. Clin Endosc. 2012;45:138-144.

4. Lanas A, Carrera-Lasfuentes P, Arguedas Y, et al. Risk of upper and lower gastrointestinal bleeding in patients taking nonsteroidal anti-inflammatory drugs, antiplatelet agents, or anticoagulants. Clin Gastroenterol Hepatol. 2015;13:906-912.

5. Strate L, Gralnek IM. ACG Clinical Guideline: management of patients with acute lower gastrointestinal bleeding. Am J Gastroenterol. 2016;111:459-474.

6. Goldstein JL, Cryer B. Gastrointestinal injury associated with NSAID use: a case study and review of risk factors and preventative strategies. Drug, Healthcare and Patient Safety. 2015;7:31-41.
7. Diaconu CC, Dediu GN, Iancu MA. Drug-induced arterial hypertension, a frequently ignored cause of secondary hypertension: a review. Acta Cardiologica 2018;73(6):511-517.

8. Chi TY, Zhu HM, Zhang M, et al. Risk factors associated with nonsteroidal anti-inflammatory drugs (NSAIDs)-induced gastrointestinal bleeding resulting on people over 60 years old in Beijing. Medicine. 2018;97:18-20.

9. Socea B, Nica AA, Bratu O, et al. Incidental finding of a sigmoid intussusception associated with rectal prolapse - a case report. Arch Balk Med Union. 2018;53(1):143-146.

10. Shin SJ, Noh CK, Lim SG, et al. Nonsteroidal anti-inflammatory drug induced enteropathy. Intestinal Research. 2017;15(4):446-455.

11. Mokhtare M, Valizadeh SM, Emadian O. Lower gastrointestinal bleeding due to non-steroid anti-inflammatory drug-induced colopathy - case report and literature review. Middle East J Dig Dis. 2013;5:107-11.

12. Colucci R, Pellegrini C, Fornai M et al. Pathophysiology of NSAID-associated intestinal lesions in the rat: luminal bacteria and mucosal inflammation as targets for prevention. Frontiers in Pharmacology. 2018;9(1340):|12-118.

13. Nagataa N, Ishiia N, Manabea N, et al. Guidelines for colonic diverticular bleeding and colonic diverticulitis: Japan Gastroenterological Association. Digestion. 2019;99(suppl 1):1-26.

14. Shadad AK, Sullivan FJ, Martin JD, et al. Gastrointestinal radiation injury: symptoms, risk factors and mechanisms. World Journal of Gastroenterology. 2013;19(2):185-98.

15. Jean H, Ashburn MF, Kalady M. Radiation-induced problems in colorectal surgery. Clin Colon Rectal Surg. 2016;29:85-91.

16. Celeste MS. Review series: hypoxia and inflammation. Reducing radiation-induced gastrointestinal toxicicty-the role of the PHD/HIF axis. J Clin Invest. 2016;126(10):37083715.

17. Fuccio L, Guido A, Andreyev JN. Management of intestinal complications in patients with pelvic radiation disease. Clinical Gastroenterology and Hepatology. 2012;10:1326-1334.

18. Mogoanta SS, Costache A, Mutiu G, et al. A nonfunctional neuroendocrine tumor of the pancreas - a case report. Romanian Journal of Morphology and Embryology. 2015;56(2 Suppl):511-519.

19. Chattopadhyay G, Ray D, Chakravartty S, et al. Formalin instillation for uncontrolled radiation induced haemorrhagic proctitis. Trop Gastroenterol. 2010; 31: 291-294.

20. Hille A, Herrmann MK, Kertesz T, et al. Sodium butyrate enemas in the treatment of acute radiation-induced proctitis in patients with prostate cancer and the impact on late proctitis. A prospective evaluation. Strahlenther Onkol. 2008;184:686-692.

21. Craighead P, Shea-Budgell MA, Nation J, et al. Hyperbaric oxygen therapy for late radiation tissue injury in gynecologic malignancies. Curr Oncol. 2011;18:220-227.

22. Abdel-Daim MM, Shaheen HM, Abushouk AI, et al. Thymoquinone and diallyl sulfide protect against fipronil-induced oxidative injury in rats. Environmental Science and Pollution Research. 2018;25(24):23909-23916.

23. Fok TC, Jan A, Peel SA, et al. Hyperbaric oxygen results in increased vascular endothelial growth factor (VEGF) protein expression in rabbit calvarial critical-sized defects. Oral Surg Oral Med Oral Pathol Oral Radiol Endod. 2008;105:417-422. 